\title{
THEORETICAL INVESTIGATION OF DIVALENT ION INSERTION INTO TUNNEL-TYPE MANGANESE DIOXIDE POLYMORPH
}

\author{
Lalu Suhaimi, Andy Tirta, Muhammad Hilmy Alfaruqi \\ Department of Metallurgical Engineering, Sumbawa University of Technology \\ lalu.suhaimi@uts.ac.id, andy.tirta@uts.ac.id, muhammad.hilmy.alfaruqi@uts.ac.id
}

\begin{abstract}
Rechargeable batteries play an important role to support the implementation of clean and renewable energy. In this aspect, post-Li-ion batteries, such as $\mathrm{Zn}$-ion batteries are receiving great attention due to their low cost and environmentally friendly. Therefore, studies of electrode materials for $\mathrm{Zn}$-ion batteries are of paramount importance. In this contribution, we present a theoretical investigation to explore the potential use of tunnel-type manganese dioxide for zinc storage material. Our calculation suggests the stability of the material for the $\mathrm{Zn}$-ion battery application.
\end{abstract}

Keywords: rechargeable battery, zinc-ion battery, density functional theory, structural evolution

Received 20 February 2020 Accepted 4 June 2020 Available online 24 June 2020

\section{INTRODUCTION}

In Indonesia, the Sustainable Development Goals are institutionalized in all level government entities. Among them, affordable and clean energy is receiving a huge interest. Indeed, due to the high population growth, the demand for energy becomes inevitable. In addition, fossil-based energy, as one of the main energy resources, is decreasing because oil reserves are dwindling. Relying on fossil-based energy is also considered detrimental to our environment [1]. Therefore, alternative energy resources, known as clean or renewable energy such as solar and wind energies have also been studied and some of them have been established in Indonesia [2].

It was reported that Indonesia has produced and utilized renewable energy at $\sim 8.66 \mathrm{GW}$ [2]. In addition, it is worth considering that these renewable energies are essentially intermittent and therefore, they require the ability to store the generated energy. In this context, batteries as energy storage would play an important role. Lithium-ion batteries (LIBs) are widely used in numerous electronic devices because of their high energies and power densities [3]. However, the components used in LIBs are considered toxic and expensive. Therefore, other environmentally friendly battery systems are preferable, for example, Zn-ion battery (ZIB) [4].

Transition metal oxides (TMOs) are one of the most attractive electrode materials for rechargeable battery applications, including manganese dioxide $\left(\mathrm{MnO}_{2}\right) . \mathrm{MnO}_{2}$ can be formed in various crystallographic structures, for example, $\alpha-, \beta-$, and $\gamma$-type [5]. The $\alpha-, \beta-$ and $\gamma-$ types are typical tunnel structure which can facilitate the storing of charge carrier ions. In order to explore the potential use of these electrode materials, besides experimental studies, a theoretical approach based on density functional theory (DFT) is also considered as an important tool $[6,7]$. In this study, we investigate the potential use of $\alpha$-type $\mathrm{MnO}_{2}$ to store $\mathrm{Zn}$ ion. Our present study offers further insight into the utilization of $\alpha$-type $\mathrm{MnO}_{2}$ for the $\mathrm{ZIB}$ application. 


\section{RESEARCH METHOD}

The calculations were performed based on DFT as implemented in the Quantum-Espresso software with the projector augmented wave (PAW) pseudopotential and the Perdew-Burke-Emzerhof (PBE) within the generalized gradient approximation (GGA) exchange-correlation functional [8-10]. Kinetic-energy cutoff of $25 \mathrm{Ry}(340 \mathrm{eV})$ and charge density cutoff of $225 \mathrm{Ry}(3060 \mathrm{eV})$ were set. The convergence threshold of of 1.0E-06 was implemented. The positions of the atoms in the $\alpha$-type $\mathrm{MnO}_{2}$ structure (space group $\mathrm{I} / \mathrm{m}$ ) were relaxed using the Broyden-Fletcher-Goldfarb-Shanno (BFGS) algorithm and all the lattice parameters and angles were allowed to move freely. The Brillouin zone was sampled using a k-point of $1 \times 1 \times 4$. For comparison purpose, k-point gamma was also used. The crystal structure models were drawn using VESTA software $[11,12]$.

\section{FINDINGS AND DISCUSSION}

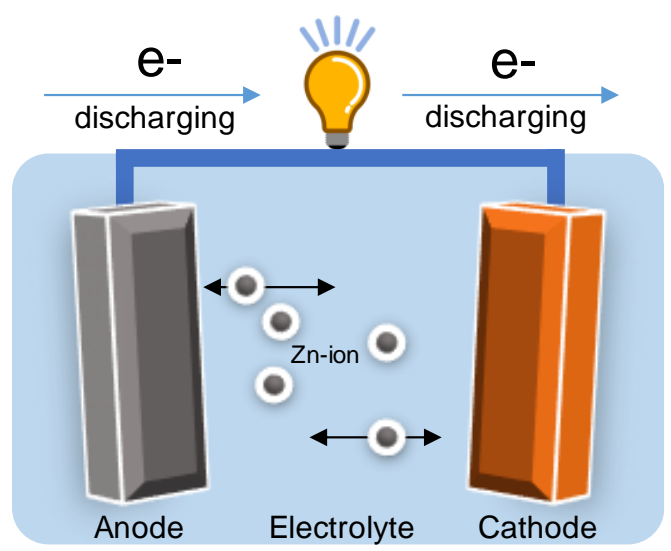

Figure 1. Illustration of ZIB components and its corresponding mechanism.

Similar to the LIB system, ZIB also consists of an anode (negative electrode), a cathode (positive electrode), and an electrolyte. The anode is generally made from $\mathrm{Zn}$ foil anode for full cell configuration while the cathode can be made from various TMO compounds such as oxide or phosphate-based. In principle, ZIBs work in the same way as LIBs. Specifically, when the battery is discharged, the $\mathrm{Zn}$-ions move through the electrolyte to the cathode side, generating the energy that can be used to power the electronic devices. Reversely, when the battery is charged, the cathode releases its Zn-ions towards the anode through the electrolyte [3]. Zn undergoes dissolution and deposition reactions during discharging and charging, respectively. The corresponding mechanism is illustrated in Fig. 1.
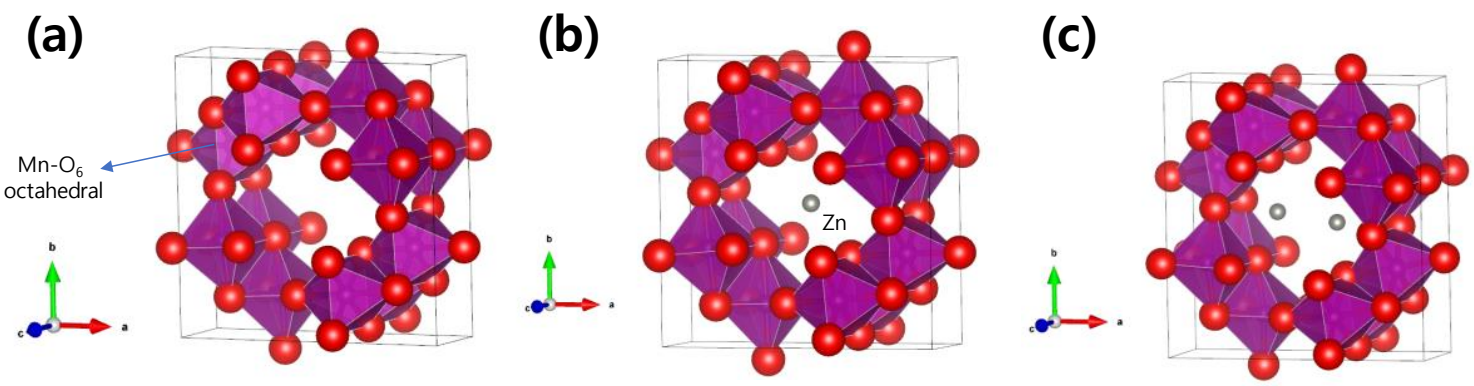

Figure 2. Relaxed structure of (a) pristine $\mathrm{MnO}_{2}$, after the insertion of (b) 1 and (c) $2 \mathrm{Zn}$-ions. 
Figure 2 illustrates the relaxed structures of pristine and $\mathrm{Zn}$-inserted $\alpha$-type $\mathrm{MnO}_{2}$. It can be observed that $\alpha$-type $\mathrm{MnO}_{2}$ has a [2 $\times 2$ ] tunnels along the $c$-axis. $\alpha$-type $\mathrm{MnO}_{2}$ possesses tetragonal symmetry with $\mathrm{I} / \mathrm{m}$ space group no. 87. Basically, the tunnels are constructed from edge-shared $\mathrm{MnO}_{6}$ octahedral units and they are able to store guest-ions [5]. The $\mathrm{Zn}$-ions are placed in the center of the $[2 \times 2]$ tunnels of $\alpha$-type $\mathrm{MnO}_{2}$. After the insertion of $\mathrm{Zn}$-ions, the tunnel feature still can be observed, suggesting the stability of $\alpha$-type $\mathrm{MnO}_{2}$ for $\mathrm{Zn}$ storage applications.

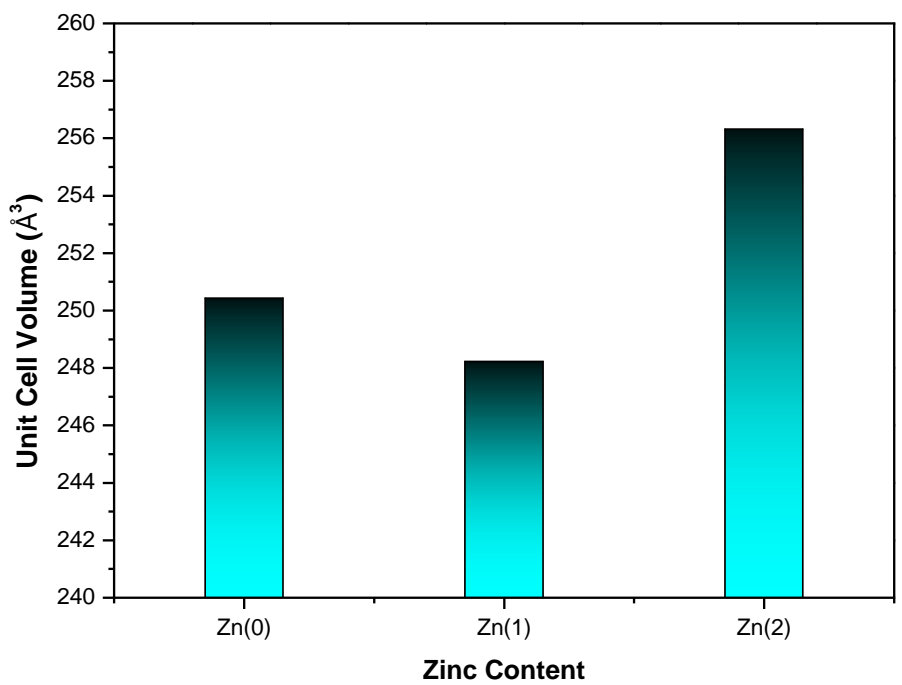

Figure 3. Unit cell volume changes as a function of $\mathrm{Zn}$ content.

It is also worth noting that after $\mathrm{Zn}$ insertion, the original structure may experience distortion. Figure 3 depicts the variation of unit cell volumes before and after $\mathrm{Zn}$ insertion. Before $\mathrm{Zn}$ insertion, the unit cell volume was measured to be $250.43 \AA^{3}$, while after the insertion of $1 \mathrm{Zn}$, it reduced to $248.22 \AA^{3}$. The contraction of the unit cell volume can be attributed to the strong cation-anion interactions. Interestingly, after $2 \mathrm{Zn}$ insertion, the unit cell volume significantly expanded to $256.31 \AA^{3}$, corresponding to the strong repulsion of each guest-ions.

The stability of the $\mathrm{Zn}$ insertion was also evaluated by calculating its insertion energy ( $\left.\mathrm{E}_{\text {ins }}\right)$. The $\mathrm{E}_{\text {ins }}$ values after 1 and $2 \mathrm{Zn}$ insertion were calculated to be -0.69 and $-0.30 \mathrm{eV}$, respectively. When k-point gamma was used, the calculated $\mathrm{E}_{\text {ins }}$ for 1 and $2 \mathrm{Zn}$ were -1.39 and $2.96 \mathrm{eV}$. The negative value indicates the insertion reaction is thermodynamically stable [7]. In addition, we also attempted to predict the possible $\mathrm{Zn}$ insertion into another $\mathrm{MnO}_{2}$ type, i.e. $\delta-\mathrm{MnO}_{2}$. Our results suggest that the $\mathrm{E}_{\text {ins }}$ after $1 \mathrm{Zn}$ insertion into $\delta-\mathrm{MnO}_{2}$ was $-2.46 \mathrm{eV}$. This indicates the possible use of $\delta-\mathrm{MnO}_{2}$ for $\mathrm{Zn}$-intercalated compound.

\section{CONCLUSION}

In conclusion, the potential utilization of tunnel-type manganese dioxide material for $\mathrm{Zn}$-ion storage was elucidated using first-principles calculations based on density functional theory. The calculations suggested that the insertion of Zn-ion also affected the unit cell volumes. In addition, insertion energy calculation indicated the stability of $\mathrm{Zn}$-ion insertion into the manganese dioxide structure. The present study may offer additional insight into the development of electrode material based on transition-metal oxides for multivalent battery applications. 


\section{REFERENCES}

[1] H. Chen, T.N. Cong, W. Yang, C. Tan, Y. Li, Y. Ding, Progress in electrical energy storage system: A critical review, Progress in natural science. 19(3) (2009) 291-312.

[2] S. Widya Yudha, B. Tjahjono, Stakeholder mapping and analysis of the renewable energy industry in Indonesia, Energies. 12(4) (2019) 602.

[3] J.-M. Tarascon, M. Armand, Issues and challenges facing rechargeable lithium batteries, Materials for Sustainable Energy: A Collection of Peer-Reviewed Research and Review Articles from Nature Publishing Group, World Scientific, 2011, pp. 171-179.

[4] G. Fang, J. Zhou, A. Pan, S. Liang, Recent advances in aqueous zinc-ion batteries, ACS Energy Letters. 3(10) (2018) 2480-2501.

[5] S. Devaraj, N. Munichandraiah, Effect of crystallographic structure of $\mathrm{MnO} 2$ on its electrochemical capacitance properties, The Journal of Physical Chemistry C. 112(11) (2008) 4406-4417.

[6] Z. Rong, R. Malik, P. Canepa, G. Sai Gautam, M. Liu, A. Jain, K. Persson, G. Ceder, Materials design rules for multivalent ion mobility in intercalation structures, Chem. Mater. 27(17) (2015) 6016-6021.

[7] A. Ismail, H.A. Prabowo, M.H. Alfaruqi, Potassium-intercalated Manganese Dioxide as Lithium-ion Battery Cathodes: a Density Functional Theory Study, Sinergi. 23(1) (2019) $55-60$.

[8] P. Giannozzi, S. Baroni, N. Bonini, M. Calandra, R. Car, C. Cavazzoni, D. Ceresoli, G.L. Chiarotti, M. Cococcioni, I. Dabo, QUANTUM ESPRESSO: a modular and open-source software project for quantum simulations of materials, J. Phys.: Condens. Matter. 21(39) (2009) 395502.

[9] P. Giannozzi, O. Andreussi, T. Brumme, O. Bunau, M.B. Nardelli, M. Calandra, R. Car, C. Cavazzoni, D. Ceresoli, M. Cococcioni, Advanced capabilities for materials modelling with Quantum ESPRESSO, J. Phys.: Condens. Matter. 29(46) (2017) 465901.

[10] J.P. Perdew, K. Burke, M. Ernzerhof, Generalized gradient approximation made simple, Phys. Rev. Lett. 77(18) (1996) 3865.

[11] K. Momma, F. Izumi, VESTA: a three-dimensional visualization system for electronic and structural analysis, J. Appl. Crystallogr. 41(3) (2008) 653-658.

[12] K. Momma, F. Izumi, VESTA 3 for three-dimensional visualization of crystal, volumetric and morphology data, J. Appl. Crystallogr. 44(6) (2011) 1272-1276. 